\title{
Interaction of valleys and circulation patterns (CPs) on spatial precipitation patterns in southern Germany
}

\author{
M. Liu ${ }^{1,2}$, A. Bárdossy ${ }^{3}$, and E. Zehe ${ }^{4}$ \\ ${ }^{1}$ State Key Laboratory of Earth Surface Processes and Resource Ecology, Beijing Normal University, Beijing, China \\ ${ }^{2}$ School of Civil, Environmental and Mining Engineering, the University of Adelaide, Adelaide, Australia \\ ${ }^{3}$ Institute for Modelling Hydraulic and Environmental Systems, University Stuttgart, Stuttgart, Germany \\ ${ }^{4}$ Institute of Water Resources and River Basin Management, Karlsruhe Institute of Technology, Karlsruhe, Germany \\ Correspondence to: M. Liu (min.liu@gmx.net) and A. Bárdossy (andras.bardossy@iws.uni-stuttgart.de)
}

Received: 19 October 2012 - Published in Hydrol. Earth Syst. Sci. Discuss.: 21 December 2012

Revised: 18 September 2013 - Accepted: 29 September 2013 - Published: 26 November 2013

\begin{abstract}
Topography exerts influence on the spatial precipitation distribution over different scales, known typically at the large scale as the orographic effect, and at the small scale as the wind-drift rainfall (WDR) effect. At the intermediate scale $(1 \sim 10 \mathrm{~km})$, which is characterized by secondary mountain valleys, topography also demonstrates some effect on the precipitation pattern. This paper investigates such intermediate-scale topographic effects on precipitation patterns, focusing on narrow-steep valleys in the complex terrain of southern Germany, based on the daily observations over a $48 \mathrm{yr}$ period $(1960 \sim 2007)$ from a high-density raingauge network covering two sub-areas, Baden-Wuerttemberg (BW) and Bavaria (BY). Precipitation data at the valley and non-valley stations are compared under consideration of the daily general circulation patterns (CPs) classified by a fuzzy rule-based algorithm. Scatter plots of precipitation against elevation demonstrate a different behavior of valley stations comparing to non-valley stations. A detailed study of the precipitation time series for selected station triplets, each consisting of a valley station, a mountain station and an open station have been investigated by statistical analysis with the Kolmogorov-Smirnov (KS) test supplemented by the Oneway analysis of variance (One-way ANOVA) and a graphical comparison of the mean precipitation amounts. The results show an interaction of valley orientation and the direction of the CPs at the intermediate scale, i.e. when the valley is shielded from the $\mathrm{CP}$ which carries the precipitation, the precipitation amount within the valley is comparable to that on the mountain crest, and both larger than the precipitation at the open station. When the valley is open to the $\mathrm{CP}$, the
\end{abstract}

precipitation within the valley is similar to the open station but much less than that on the mountain. Such phenomenon where the precipitation is "blind" to the valleys at the intermediate scale conditioned on CPs is defined as the "narrowvalley effect" in this work. Such an effect cannot be captured by the widely used elevation-precipitation relationship, which implies that the traditional geostatistical interpolation schemes, e.g. ordinary kriging (OK) or external drift kriging (EDK) applying digital elevation model (DEM) as external information, are not sufficient. An interpolation experiment applying EDK with orographic surrogate elevation defined in this paper as auxiliary information to account for the valley effects shows improvement for the cross-validation.

\section{Introduction}

Precipitation is characterized by remarkable spatial and temporal variability at different space- and timescales (Bidin and Chappell, 2003; Nezlin and Stein, 2005; Jeniffer et al., 2010; Langella et al., 2010), and the spatio-temporal variability is of critical importance for a wide range of hydrometeorological and hydro-geological applications. For instance, the persistent precipitation pattern will shape the terrain through erosion (Anders et al., 2006), and a co-evolution of topography precipitation can be observed (Roe, 2003; Stolar et al., 2007). Numerous studies have also shown that the spatial variability of rainfall is essential for runoff generation processes and flood forecasting (Koren et al., 1999; Arnaud et al., 2002). The spatial precipitation variability is 
also a major source of the uncertainty of hydrological models (Younger et al., 2009). The local and regional water balance is also determined by precipitation patterns at the corresponding scales (Fekete et al., 2004). Furthermore, detailed knowledge on precipitation patterns can be used to optimize the design of rain-gauge networks (Cheng et al., 2008), such that a limited number of stations can adequately represent the underlying rainfall field.

Topography, among many other factors, has profound effects on spatial distribution of precipitation. Thanks to the readily available digital elevation model (DEM) data, topographic effects have been extensively studied. Statistical analysis and numerical simulation are the two major tools for investigation of topographical precipitation. Meteorological precipitation models can generate spatial precipitation distribution, but require detailed input of environmental parameters, such as temperature, lapse rate, wind, etc., which renders the modeling practice rather location- and event-specific (Smith, 2006). Furthermore, even informed by very detailed data, current models still have a limited accuracy and capacity in resolving the small-scale precipitation. Due to the limitation of the modeling approach, statistical studies on topography-altered spatial precipitation have been very popular, which range from pure precipitation-altitude relationship (Sevruk and Nevenic, 1998) to multivariate regression models relating precipitation to multiple topographic parameters, including elevation, slope, orientation and exposure (Prudhomme and Reed, 1998; Daly et al., 2002; Sun et al., 2008), and in some cases also wind parameters (Johansson and Chen, 2003).

The orographic effect at the large scale and the wind-drift rainfall effect (WDR) at the small scale are the most widely reported topographic effects on precipitation in the literature. The orographic effect refers to the forced uplifting and consequently cooling down of moist air at the windward side of the mountain to generate precipitation and the descending and warming up on the lee side of the mountain to reduce the precipitation, known as "rain shadow". Orographic precipitation occurs at large scales consisting of primary mountain valleys, and the associated spatial distribution of precipitation can usually be reflected by an elevation-precipitation relationship. The orographic effect has been widely studied and confirmed by theory (Houze, 1993; Haven, 2004), modeling (Jiang, 2007), and statistical analysis (Basist et al., 1994; Weisse and Bois, 2001; Marquínez et al., 2003). In contrast, the WDR effect focuses on the precipitation trajectories affected by topography-conditioned perturbations of the local wind field at a much finer scale featured by microtopography, which is not part of the rainfall generation process. WDR has also been extensively investigated with both observation data and fluid mechanical models (Sharon and Arazi, 1997; Blocken et al., 2005; Lehning et al., 2008). In general, the orographic effect entails precipitation climatology at the scale of around or larger than $100 \mathrm{~km}$, whereas the WDR effect describes the redistribution of rainfall by mi- crotopographic features of less than around $1 \mathrm{~km}$. Limited attention has been paid to precipitation patterns at the intermediate scale consisting of the secondary mountain valleys, which remains a scale gap in describing the spatial variability of precipitation. Furthermore, neglecting the interaction of topography with climatology in most studies has also left a theoretical gap in studying precipitation patterns.

Faures et al. (1995) and Merz and Bárdossy (1998) have shown that the small-scale spatial precipitation variability has a strong impact on runoff processes for very small areas. However, when the resolution of catchment models goes beyond $1 \mathrm{~km}$, which is normal for medium- and large-size basins, the spatial variance resulting from WDR effect will be homogenized out, and is thus not very relevant for the areal precipitation of each single grid. In such cases, the spatial variance at the intermediate scale corresponding to the resolution of hydrological models becomes increasingly critical.

Studies on spatial precipitation reported in the literature are usually undermined by two problems: (i) the spatial locations of stations tend to be biased to easily accessible sites; (ii) rain-gauge networks seldom have the spatial density that is fine enough to sample the small- and intermediate-scale variability of precipitation, therefore only the large-scale precipitation structure can be resolved. One climatological study with observation data that is closer to the intermediate scale defined in this paper is presented by Frei and Schär (1998) (about $25 \mathrm{~km}$ ), which concludes that a simple precipitationheight relationship does not exist in the Alpine region. As with many other studies, it investigates only the effects of topography without considering interactions with other factors, especially the atmospheric conditions. Some other studies have tried to link the precipitation patterns to circulation patterns (CPs), but only at the very large (country or continental) scale and without consideration of the topographic effects (Busuioc et al., 2001; Haston and Michaelsen, 1997). To the authors' knowledge, only Wastl and Zängl (2008) have investigated the mountain-valley precipitation difference with consideration of the climatology at the intermediate scale. In this paper, the authors tried to relate the precipitation difference to simulated wind by the MM5 model at $700 \mathrm{hPa}$ level and the vertical moisture profile from 600 to $850 \mathrm{hPa}$. By careful selection of mountain-valley station pairs, they excluded the precipitation difference caused by horizontal gradient to see the pure effects of local topography. The raingauge observations combined with the meteorological simulations showed that, in some cases the valley stations receive comparable rainfall to the mountain stations, while in other cases the precipitation exhibits a wind direction dependent difference, therefore a systematical mountain-valley precipitation relationship could not be concluded.

This paper revisits the issue of spatial precipitation variability, but focuses on the intermediate scale characterized by secondary mountain-valleys using a statistical approach. The high-density rain gauge network with long-term observations in southern Germany enables the investigation 


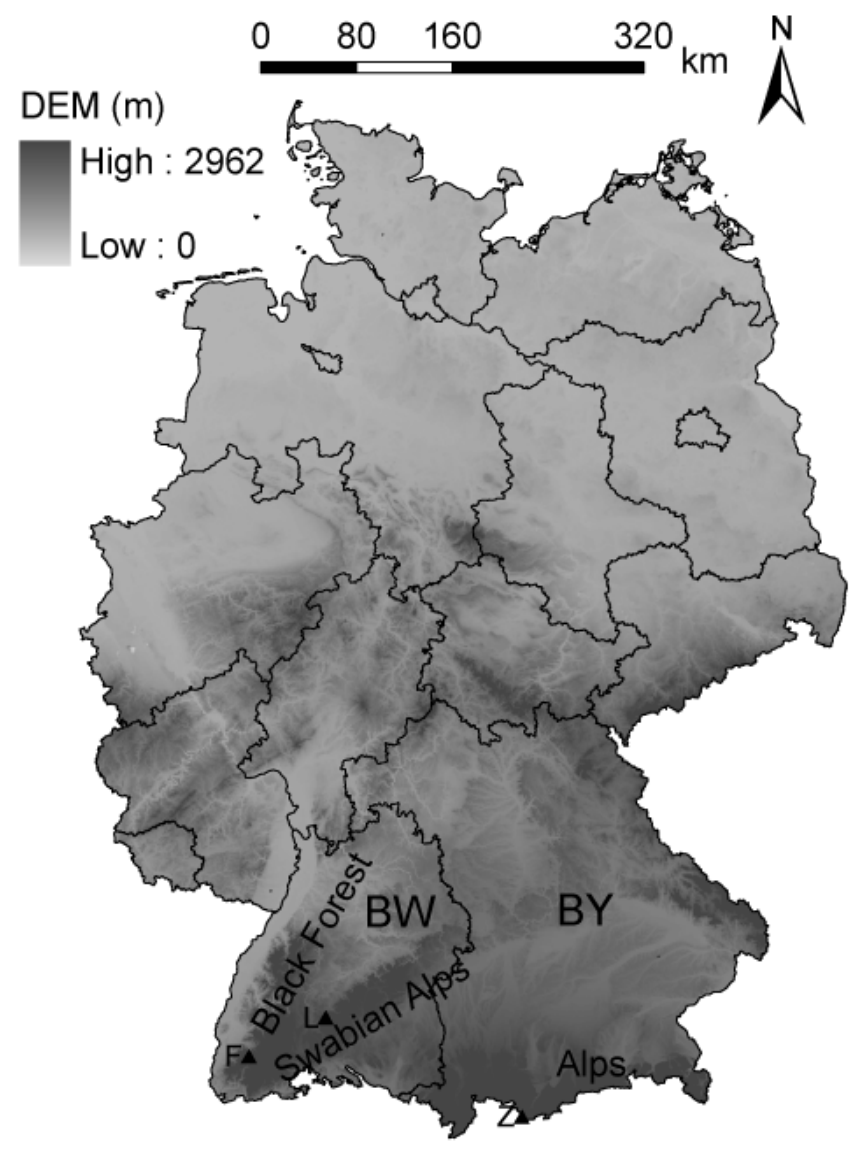

Fig. 1. Study areas (F, L and Z are the local peeks Feldberg, Lemberg and Zugspitze in the study areas, respectively).

of mountain-valley precipitation difference due to the interaction of topography with CPs at the intermediate scale to close the aforementioned research and scale gaps in precipitation patterns. The study applies both parametric and nonparametric tests to analyze daily precipitation for all days and for days with a given CP type. One-way analysis of variance (One-way ANOVA) test is applied as a parametric method to compare the mean precipitation, whereas the non-parametric Kolmogorov-Smirnov (KS) test is applied to compare the empirical distribution. The consequence of neglecting the precipitation patterns at the intermediate-scale during the interpolation procedure is demonstrated with traditional OK and EDK, which shows systematic bias.

The paper is outlined as follows: Sect. 2 describes the studying area and the database. Following the introduction of the CP classification, the valley and non-valley stations identified for the study areas will be presented; Sect. 3 will first demonstrate the results of a simple statistical analysis through scatter plots of precipitation and elevation, and then the detailed analysis with statistical tests for the selected station triplets. Section 4 will illustrate the consequences of neglecting of the precipitation variability at the intermediate scale during interpolation by showing the bias of $\mathrm{OK}$ and
EDK in one of the study areas, and the possibility to consider it by applying orographic surrogate elevation as auxiliary information for EDK. The main findings are summarized in Sect. 5 .

\section{Study area and data}

\subsection{Study area}

Because this study relies mainly on statistical analysis which demands detailed observational data, the two southernmost German federal states have been taken as the study area: Baden Wuerttemberg (BW, $35751 \mathrm{~km}^{2}$ ) and Bavaria (BY, $70551 \mathrm{~km}^{2}$ ) (see Fig. 1), both with good precipitation data availability and rich topographic features. To describe the directions of moisture flow more accurately, the two states are investigated separately in this work. Baden-Wuerttemberg is located in southwest Germany and contains two mountain ranges, the Black Forest of medium elevation in the west and the Swabian Alps of lower elevation in the east. The Swabian Alps lie between the Danube in the southeast and the Upper Neckar in the northwest. In the southwest they approach the high-elevation area of the Black Forest. The highest peak of the region is Lemberg $(1015 \mathrm{~m})$. The area's profile resembles a high plateau, which rises abruptly in the northwest with a steep escarpment up to $400 \mathrm{~m}$, while over the top it is flat or gently hilled. The Black Forest occupies a $200 \mathrm{~km} \times 60 \mathrm{~km}$ bell-shaped region tilted to northeast and bounded by the Rhine valley in the west and south. The highest peek in the Black Forest stretches to $1493 \mathrm{~m}$ at Feldberg in the southwest and is surrounded by a high plateau, which reduces its elevation, while extending to the northeast and rising again after a few kilometers. The state Bavaria contains the middle-north ranges of the Alps which defines its border with Austria. The Alps in Bavaria are characterized by high mountains with a peak of $2962 \mathrm{~m}$ at the Zugspitze. The main profile of the mountains extends from west to east, but locally, mountain crests of different orientations can be observed. The entire study domain contains mountains ranging from low, medium to high altitude, which offers a possibility for a comprehensive study of mountain-valley precipitation variability over different elevations. For the study area, a $30 \mathrm{~m}$ DEM is available from the local environmental agency, and is resampled to $100 \mathrm{~m}$ in ArcGIS (see Fig. 1).

\subsection{Precipitation data}

The study areas are located in a temperate climate region with abundant precipitation, with annual precipitation ranging from 700 to $1800 \mathrm{~mm}$. The German Weather Service (DWD) has operated a high-density rain-gauge network using OTT weight-based pluvio-devices in these areas - in Baden-Wuerttemberg there are in total 294 stations with a mean gauge distance of around $10 \mathrm{~km}$, and in Bavaria 1239 stations with a mean distance of around $7.5 \mathrm{~km}$. In certain 


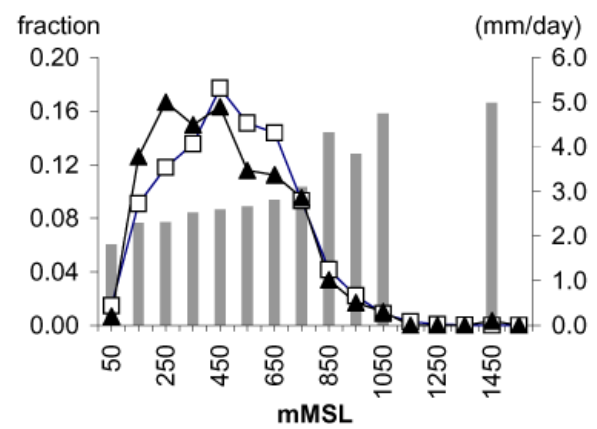

(a) BW

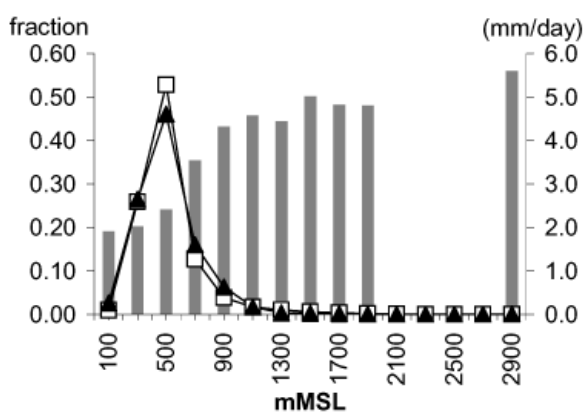

(b) BY

Fig. 2. Hypsometric distribution (dark triangle, left ordinate), altitudinal distribution of rain gauges (light square, left ordinate) and mean precipitation (gray bars, right ordinate) for each elevation band in BW and BY. The hypsometric distribution was determined from a topographic data set with a resolution of $100 \mathrm{~m}$.

Table 1. CPs classified by automated fuzzy rule-based algorithm.

\begin{tabular}{cccclcc}
\hline CP & Direction & WI & CP & Direction & WI \\
\hline & CP01 & NE & 7.5 & CP10 & W, NW & 29.2 \\
CP02 & E & 3.3 & CP11 & SW & 4.5 \\
CP03 & SE & 1.7 & CP12 & SW & 4.5 \\
CP04 & SE, E & 2.8 & CP13 & W & 6.3 \\
BW & CP05 & SW & 15.4 & CP14 & NW & 13.7 \\
& CP06 & W, SW & 2.9 & CP15 & SE & 3.1 \\
CP07 & E, SE & 6.8 & CP16 & S & 3.0 \\
CP08 & S & 8.8 & CP17 & SW & 19.0 \\
CP09 & NE, N & 16.5 & CP18 & W & 20.1 \\
CP01 & NW & 7.5 & CP12 & NW & 3.4 \\
CP02 & S, SE & 2.1 & CP13 & N & 18.8 \\
CP03 & S, SW & 9.3 & CP14 & W & 23.4 \\
CP04 & W & 4.0 & CP15 & S, SW & 7.6 \\
CP05 & SW & 20.1 & CP16 & S, SE & 3.1 \\
CP06 & W & 3.9 & CP17 & N & 15.4 \\
CP07 & E, SE & 5.4 & CP18 & S, SE & 5.7 \\
CP08 & SE & 3.3 & CP19 & SE & 5.1 \\
CP09 & W & 16.7 & CP20 & W & 13.3 \\
CP10 & E & 15.6 & CP21 & NE & 6.4 \\
CP11 & NW & 16.5 & & & \\
\hline
\end{tabular}

regions of the study areas, the mean gauge distance reaches $2.5 \mathrm{~km}$, with a minimum distance of around $1.5 \mathrm{~km}$. The station data span over $40 \mathrm{yr}$ from 1961 to 2007, but the valid station observations vary over time. The average number of daily reported stations is lower than the total number of stations due to the missing records at some of the stations, and in general the average number of daily stations has decreased with time because of the deployment of radar stations. However, the station density in the two data sets exhibits only slight variations until year 2000. In this study, only stations with precipitation records longer than $10 \mathrm{yr}$ are considered for the statistical analysis. While the high-density network enables the statistical investigation of the mountain-valley precipitation variation at the intermediate scale, the long-
Table 2. Parameters used for valley detection.

\begin{tabular}{lcc}
\hline & BW & BY \\
\hline$L[\mathrm{~m}]$ & 3200 & 3000 \\
$l[\mathrm{~m}]$ & 1000 & 800 \\
$\Delta h_{1}[\mathrm{~m}]$ & 180 & 180 \\
$\Delta h_{2}[\mathrm{~m}]$ & 150 & 150 \\
$\Delta h_{3}[\mathrm{~m}]$ & 150 & 150 \\
$n[-]$ & 30 & 30 \\
\hline
\end{tabular}

term records guarantee the reliability of the analysis. We acknowledge that the precipitation might be associated with measurement errors and uncertainties, which, however, will not be addressed in this paper by assuming spatially homogeneous rainfall errors.

Some descriptive statistics in Fig. 2 show the hypsometric distribution, the altitudinal distribution of rain gauges and the corresponding mean daily precipitation of stations lying in each elevation band. In principal, the altitudinal distribution of rain gauges follows the hypsometric distribution curve, which appears to be a more or less equally representation of precipitation of different elevation. However, as shown by the mean precipitation of different elevation band in Fig. 2, there is a gap in the mean precipitation bars, which reflects missing observation at the higher elevations in both areas (1050 1450 $\mathrm{m}$ in BW and $1900 \sim 2900 \mathrm{~m}$ in BY). If such areas are neglected, the precipitation seems to demonstrate an increasing trend with increasing elevation up to certain elevation and keeps constant at the higher elevation in both $\mathrm{BW}$ and $\mathrm{BY}$.

\subsection{Circulation Patterns}

Circulation pattern $(\mathrm{CP})$ is the mean air pressure distribution over an area, and is defined using 500 or $700 \mathrm{hPa}$ geo-potential anomalies. Any given circulation type persists 


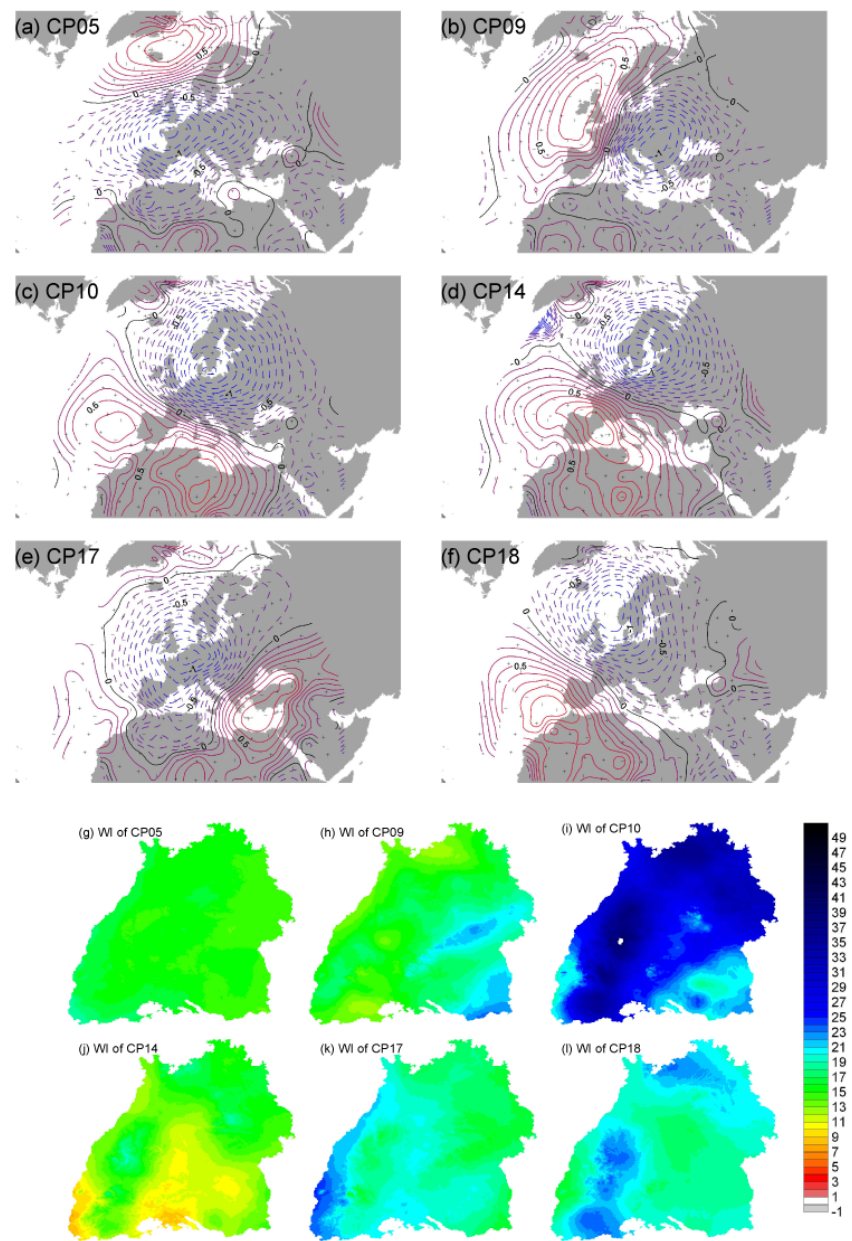

Fig. 3. Geopotential anomalies and wetness index of wet CPs for BW.

for several days and during this time the main features of weather remain mostly constant across the CP-covered region. Then through a rapid transition, another $\mathrm{CP}$ will emerge. Similar CPs will generate similar weather conditions, and can be classified by their characteristic pressure field as either wet or dry corresponding to a low (cyclone) or high pressure center (anti-cyclone). The direction of moisture flow can be considered to be identical to the circulation pattern.

In this work, the CPs are classified with the automated fuzzy rule-based algorithm by Bárdossy et al. (2002); Bárdossy (2010). Fuzzy rules specify the position of high- and low- pressure anomalies and are then optimized automatically with the simulated annealing (SA) algorithm. With the help of the optimized fuzzy rules, the pressure fields, i.e. the large-scale atmospheric CPs, can be classified into groups associated with certain local precipitation characteristics (Bárdossy et al., 2005). The ratio of mean daily precipitation of a given $\mathrm{CP}$ to the climatological average, i.e. the mean daily precipitation of all days is referred to as the wetness index
(WI). In this paper, the wetness index is scaled by 10 , therefore a value higher than 10 indicates "wet", e.g. if the wetness index is equal to 20 , it means it is twice as wet as the climatic average. To consider more accurately the direction of moisture flow, the CPs in the two states are classified individually. In BW, 18 CPs are obtained, with 6 of them being so-called wet CPs, whereas in BY, 8 out of $21 \mathrm{CPs}$ are wet (see Table 1). Because the wet CPs generate the major rainfall, they are elaborated more in details in this research. Figures 3 and 4 show geopotential anomalies and the scaled wetness index (WI multiplied by 10) of the wet CPs of BW and BY, respectively.

\subsection{Identification of valley stations}

Because the goal of this paper is to investigate the effects of narrow-steep valleys, the first step is to define and identify the target valleys, i.e. to differentiate the stations in narrowsteep valleys from the other stations. Valleys are formed by either river or glacial erosion, or sequential occupation of one after the other (Montgomery, 2002). With its erosion, transportation, and sedimentation functions, rivers will form valleys with different cross-section shapes depending on the surrounding topography - rivers with steep gradients produce steep walls with a narrow bottom, and rivers with smaller slopes will result in broader and gentler valleys, with the resulted valleys being commonly V-shaped. At the lowest reach of a river, a floodplain comes into being by sedimentation. The invasion and recession of the glaciers will form the U-shaped valleys. Characteristics such as bottom width, shoulder width, ridge-crest-to-valley-bottom relief and crosssectional area are used to classify the valley shapes. In this study, criteria based on elevation difference for all cross sections passing a given location are selected. Whether a given point $P$ with elevation $Z_{p}$ is located in valley or non-valley area is evaluated by the following trial-and-error procedure (illustrated in Fig. 7):

1. A vertical plain passing point $P$ intersects the terrain at a planar curve $S$. The plain will be rotated $N$ times such that its horizontal angle (with regard to the east) changes from $0^{\circ}$ to $360^{\circ}$ at an interval of $\frac{360}{N}$;

2. For each rotation, search on the plain for the lowestelevation $\left(Z_{1}^{1}\right.$ and $\left.Z_{\mathrm{r}}^{1}\right)$ on each side of the station along the curve within a horizontal distance $l$;

3. Search for the highest-elevation $Z_{1}^{\mathrm{h}}$ on one side of the station within a horizontal distance $L(L>l)$, the actual distance from the highest point to point $P$ is recorded as $L_{1}$;

4. Search for the highest-elevation $Z_{\mathrm{r}}^{\mathrm{h}}$ on the other side of the station within a distance of $L-L_{1}$;

5. For a station to be recognized as within narrow-steep valley, $n$ out of $N$ plain should satisfy the following 


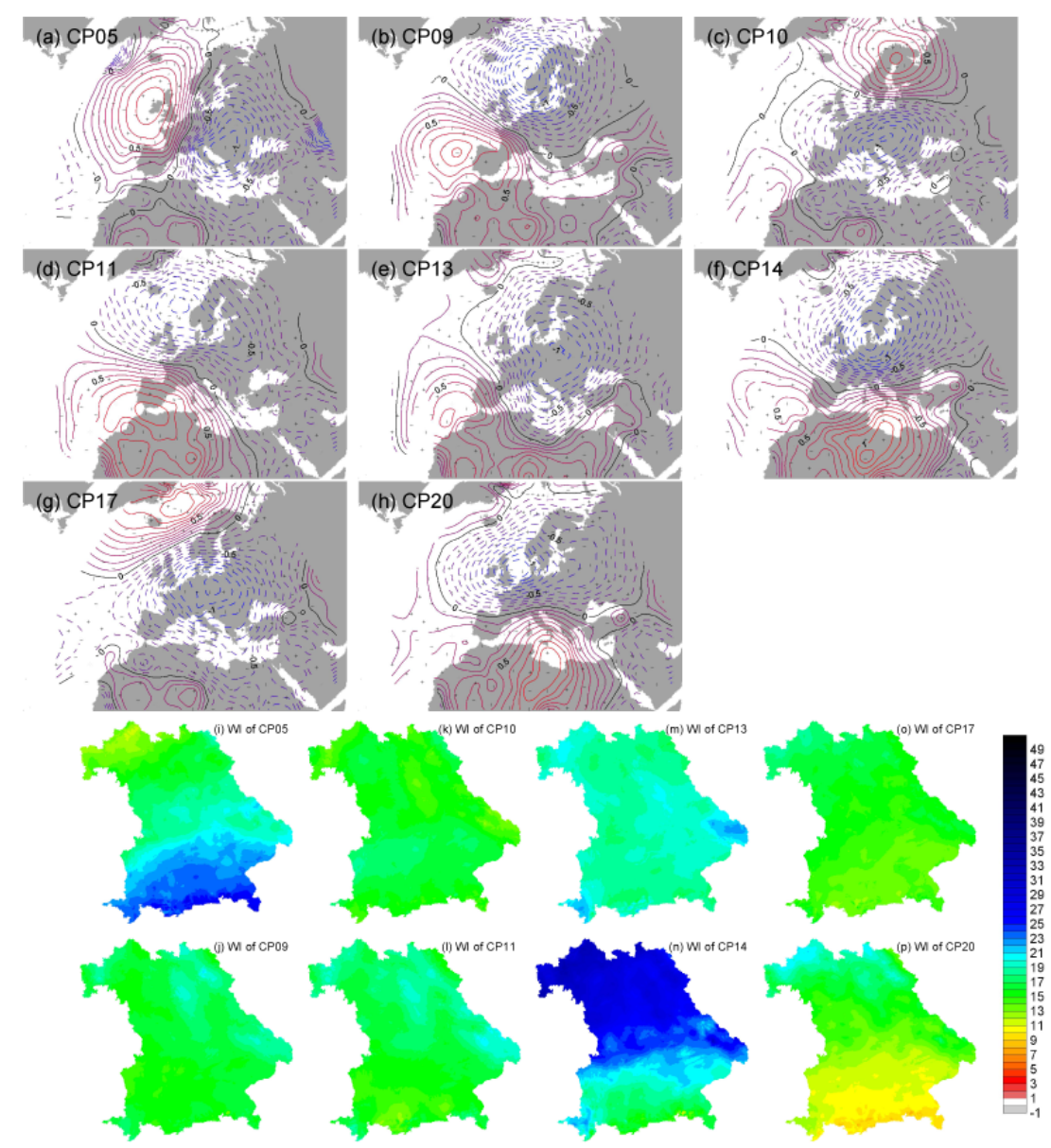

Fig. 4. Geopotential anomalies and wetness index of wet CPs for BY.

conditions:

$$
\begin{aligned}
& \max \left(Z_{1}^{\mathrm{h}}, Z_{\mathrm{r}}^{\mathrm{h}}\right)-\min \left(Z_{1}^{1}, Z_{\mathrm{r}}^{\mathrm{l}}\right) \geq \Delta h_{1} \\
& \min \left(Z_{1}^{\mathrm{h}}, Z_{\mathrm{r}}^{\mathrm{h}}\right)-\max \left(Z_{1}^{1}, Z_{\mathrm{r}}^{\mathrm{l}}\right) \geq \Delta h_{2} \\
& \max \left(Z_{1}^{\mathrm{h}}, Z_{\mathrm{r}}^{\mathrm{h}}\right)-Z_{p} \geq \Delta h_{3} .
\end{aligned}
$$

Except $N$ being set to 72 , all the other parameters $\left(L, l, \Delta h_{1}, \Delta h_{2}, \Delta h_{3}, n\right)$ are determined by trial-and-error procedure started from reasonable initial values and changed by visual comparison with the DEM map. The parameters of valley identification for both study areas are listed in Table 2 .

After several iterations, a nearly perfect identification of valley stations is achieved, with 2 or 3 stations being manually adjusted by visual inspection. Figures 5 and 6 demonstrate the identified valley stations together with their station numbers for BW and BY, respectively. For detailed investigation with selected station triplets, the non-valley stations are further defined as mountain stations on mountain top and open stations in open low area.

\section{Statistical analysis}

A preliminary study of the mountain-valley station difference is demonstrated by scatter plots of station precipitation and elevation. The scatter plots are shown for general days, as wells for specific CPs. Furthermore, statistical analysis with the KS test and One-way ANOVA test for selected stations triplets then gives insight into the spatial precipitation patterns.

\subsection{Scatter plot of altitude vs. precipitation}

Figure 8 shows the scatter plot of mean daily precipitation at both the valley and non-valley stations for BW. The valley stations are given as circles with the corresponding station number. The trend line of the valley stations lies above the trend line of the mountain stations, and most valley stations appear on the upper left part of the scattered points and above the all-station trend line, except two groups of stations marked by the red and blue ovals in Fig. 8. However, closer investigation shows that most stations from the two groups are located on either side of the Swabian Alps (BW-A and 


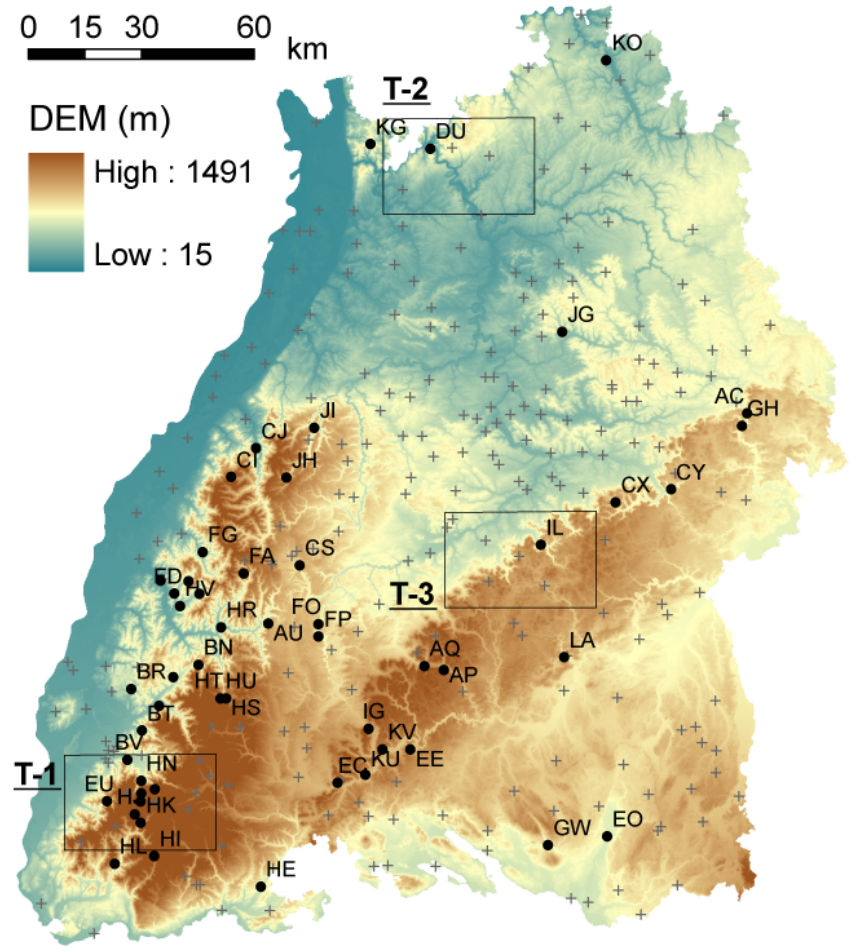

Fig. 5. Valley (solid circle) with station numbers and non-valley (cross) stations in BW (the rectangles indicate the location of the selected triplets).

BW-B in Fig. 9a), where a smaller regional mean precipitation occurs. If the two localized groups are excluded, the trend line of the valley stations will exhibit a much higher slope than the non-valley stations, which implies that the valley stations behaves systematically different from the nonvalley stations. If the station elevations and their precipitation of each localized group are plotted, they again show characteristics as in Fig. 8, i.e. larger intercept and higher slope (see Fig. 9b and c). Of note are four stations (CS, HE, EO, $\mathrm{GW}$ ) enclosed in the red oval in Fig. 8 but not located in the Swabian Alps, which are not shown in Fig. 9b. These 4 stations appear to behave differently with regards to the majority of the valley stations, but when comparing to its neighboring stations, they still demonstrate the typical characteristics of valley stations, which is trivial to be shown here. Another single exceptional station $\mathrm{KO}$ is a station in the river valley, which is not actually narrow and steep. We do not exclude the possibility that some exceptional valley stations do not follow our assumption, such as station EC in Fig. 9c, which may be caused by very specific local geographical and meteorological conditions.

Figure 10 shows the scatter plot of BY. As in the case of $\mathrm{BW}$, the scatter plot shows a clear distinction of valley and non-valley stations with some localized groups. For example, the group of valley stations BY-A (L38, L45, N09, $\mathrm{N} 38, \mathrm{Q} 42, \mathrm{~T} 04, \mathrm{U} 01, \mathrm{U} 27, \mathrm{~W} 06)$ in the low mountain region

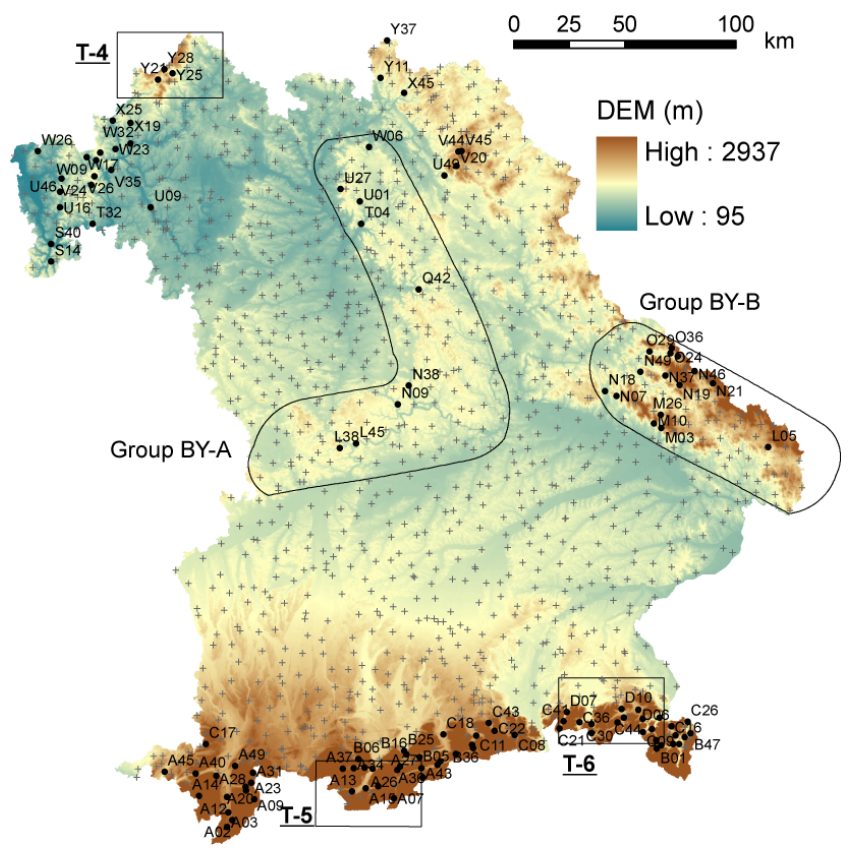

Fig. 6. Valley (solid circle) with station numbers and non-valley (cross) stations in BY (the rectangles indicate the location of the selected triplets, and the irregular shapes indicate the location of the outliers)

located in the middle of the state are mixed in the cluster of non-valley stations because of lower regional precipitation; the valley stations in the middle-east of the state (L05, M03, M10, M26, N07, N18, N19, N21, N37, N49, O13, O24, O29, O36) form another outlier group in the scatter plot. When plotted locally, the trend line of the valley stations of group BY-A is almost flat, which seems contradictory to the results obtained in BW. However, this area contains two mountain ranges in different directions. Stations in the north-south mountain ranges appear mostly on the upper edge of the scattered points, whereas four other stations (L38, L45, N09, N38) are mixed with non-valley stations exhibiting a lower amount of precipitation (Fig. 11a). This implies that the amount of precipitation at the valley stations may be related to the mountain/valley orientation. The trend line of group BY-B shows again the general characteristics when plotted locally (Fig. 11b). Some stations, such as N18, N49, N07 show exceptionally low precipitation, because they are located at the fringe of the mountainous area. Individual exceptional stations including Y37, A07 and W32, may be caused by very specific local geographic conditions, and are beyond the scope of discussion of this paper.

The phenomenon that valley stations lie in the upper part of the scatter plot can be interpreted in two ways by comparing the valley station with either a station of higher elevation but similar precipitation, or a station of lower precipitation but comparable elevation. For a valley station and a non-valley station located at the same elevation, the valley 


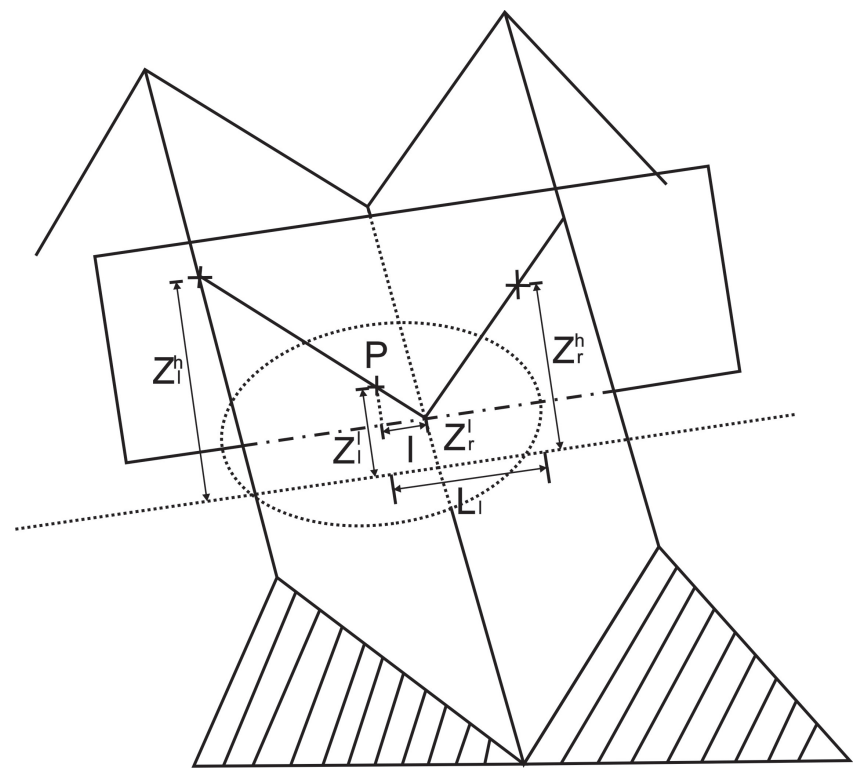

Fig. 7. Scheme of valley identification $(P$ is the point to be identified. The algorithm searches both the highest and the lowest points on both sides of $P$, if certain elevation difference can be maintained, then it indicates a possible valley formation).

station receives more rainfall, which reflects higher areal precipitation in the mountainous region. For example, it can be seen that station Eberbach (DU), which is a valley station, receives higher precipitation than the nearby station Spechbach (KI) on the open area (see Fig. 8). Sometimes, even an open station is located at a higher elevation than a valley station; it may receive less precipitation, as for example Titisee (GZ) comparing to Zastler (EV) (see Fig. 8). Alternatively, it can be interpreted in another way, in that a valley station receives comparable rainfall to a station located at a much higher elevation, for example, Waldbrunn (KF) with Eberbach (DU) in Fig. 8. The precipitation relationship among the station triplet such as DU/KI/KF contains very useful information of precipitation patterns and will be investigated in further detail.

\subsection{Scatter plot with consideration of CPs}

Further investigation of scatter plots of daily precipitation also demonstrates similar features that valley stations lie above other stations in the scatter plots, although the distribution of the valley and non-valley stations in the scatter plots varies from day to day. Figure 12 shows the scatter plots of the mean daily precipitation of all the wet CPs of BW. The locations of valley and non-valley points in the scatter plots change for different CPs. For CP10 the valley and non-valley stations are rather mixed, but for other wet CPs valley stations are on the upper edge. For CP05 the valley and nonvalley stations are clearly separated, while in CP09 some of them become mixed, which may imply that valley stations re-

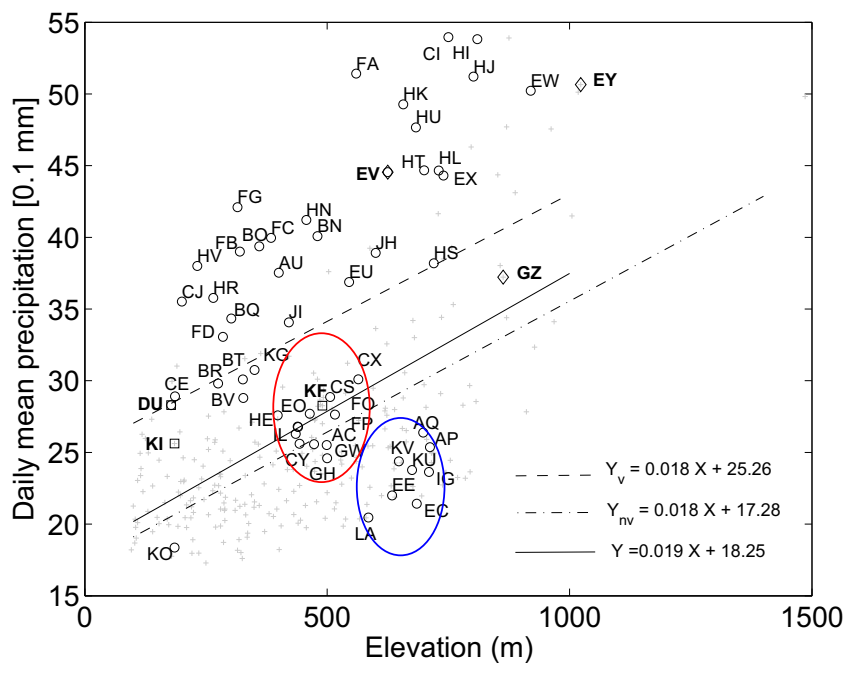

Fig. 8. Scatter plot of mean daily precipitation vs. elevation for BW (circles indicate valley stations, and crosses indicate non-valley stations).

ceiving comparable precipitation as some non-valley stations under CP05 receive less precipitation under CP09, i.e. the precipitation amount at a station depends not only on whether it is a valley station, but also on the $\mathrm{CP}$ of that day. Whether the assumption is true or not should be checked through detailed comparison of the precipitation time series at neighboring valley and non-valley stations.

\subsection{Statistical test of precipitation time series for selected station triplets}

To confirm whether the valley-mountain precipitation difference is affected by CPs, statistical tests of selected valleymountain-open station triplets were performed. To properly reflect the local spatial precipitation pattern, the three stations of a triplet should be geographically close. Due to the general problem of rain gauge availability in mountainous regions, there are only very few such ideal station configurations available. Another problem is that for stations deep inside the mountain range, there are no open stations in the nearby neighborhood. In such cases, the closest open station is taken. Nevertheless, six station triplets, from T-1 to T-6, three for each state satisfying the requirements, were selected and analyzed. The location of the station triplets are shown in Figs. 5 and 6. The name, ID number and elevation of the stations are shown in Table 3. To have a clear impression about the local topography, Google Map terrain with a very fine resolution has been used as auxiliary information.

Two different statistical tests are conducted for the precipitation time series: the non-parametric two-sample $\mathrm{KS}$ test of the empirical cumulative distribution (CDF) and the parametric one-way ANOVA test of the mean precipitation. The nullhypothesis of the KS test is that the two stations are drawn from the same continuous distribution, and for the One-way 
Table 3. Selected stations triples for statistical analysis.

\begin{tabular}{|c|c|c|c|c|c|c|}
\hline & \multicolumn{2}{|c|}{ Mountain station } & \multicolumn{2}{|c|}{ Valley station } & \multicolumn{2}{|c|}{ Open station } \\
\hline & Name (No.) & Elev. (m) & Name & Elev. (m) & Name & Elev. (m) \\
\hline $\mathrm{T}-1$ & Hofsgrund (EY) & 1023 & Zastler (EV) & 625 & Titisee (GZ) & 863 \\
\hline $\mathrm{T}-2$ & Waldbrunn (KF) & 490 & Eberbach (DU) & 178 & Spechbach (KI) & 185 \\
\hline $\mathrm{T}-3$ & Eningen $(\mathrm{CW})$ & 705 & Urbach (IL) & 435 & Reutlingen (FT) & 360 \\
\hline $\mathrm{T}-4$ & Kreuzberg (Y20) & 855 & Wildflecken (Y21) & 507 & Geroda (X43) & 550 \\
\hline $\mathrm{T}-5$ & Kreuzeckhaus (A08) & 1652 & Garmisch (A15) & 719 & Uffing (C32) & 730 \\
\hline $\mathrm{T}-6$ & Rauschberg (C45) & 1640 & Ruhpolding (C44) & 692 & Neukirchen (D47) & 712 \\
\hline
\end{tabular}

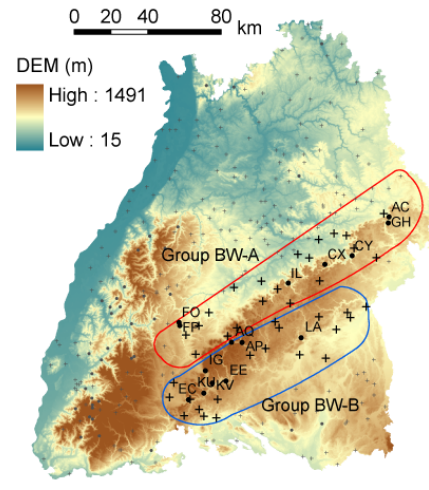

(a)

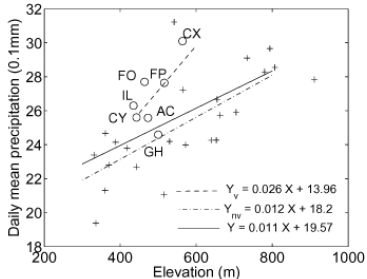

(b)

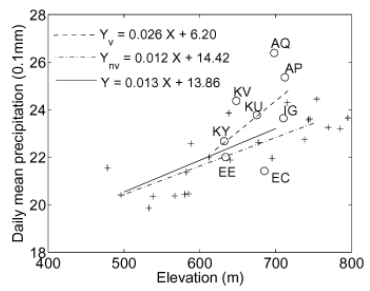

(c)

Fig. 9. Location of outlier stations and locale scatter plots of Baden Wuerttemberg (a). The location of two groups of outliers, Group BW-A and Group BW-B; (b) Scatter plot of Group BW-A; (c) Scatter plot of Group BW-B.

ANOVA test it is that the mean precipitation of the two or three stations are the same. As the KS test is free of the normality assumption of the underlying data, we focus on strong conclusions (rejection of null hypothesis which states that the two stations are drawn from the same continuous distribution). In the case that KS test does not generate favorable conclusion, the ANOVA test is used as a substitute to seek a conclusion complying with the assumptions, e.g. to reject the null hypothesis that the mean precipitation of the valley station is indifferent from the open station when it is shielded from the moisture flow. Although one-way ANOVA is known to be based on the assumption of the normal distribution of underlying data, it is robust with respect to modest violation of the assumption given that the samples are mutually independent (Krishnaiah, 1980). In the case that the combination of the two tests does not give a desired result, the $p$ value is referred to as a measurement of similarity of the stations. The tests are applied with the valley station being the reference

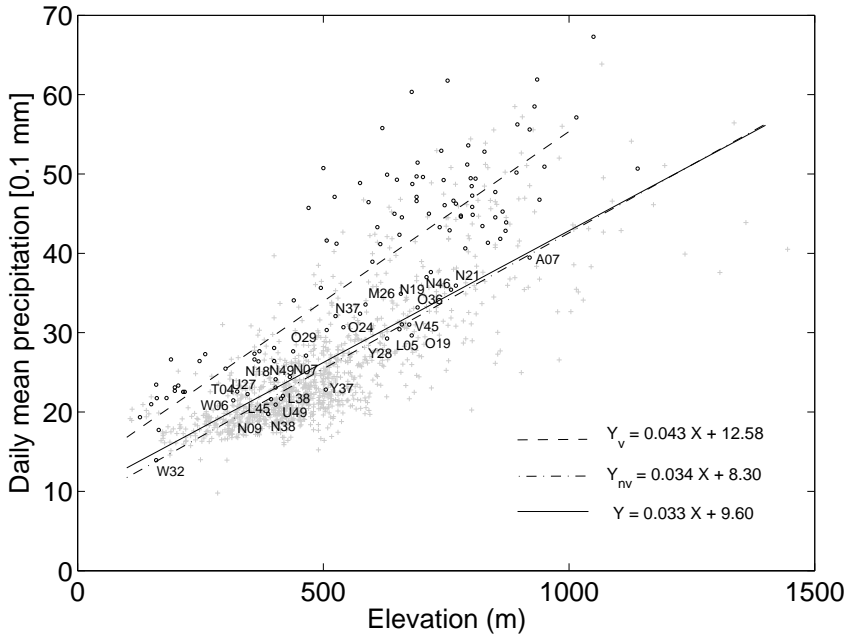

Fig. 10. Scatter plot of mean daily precipitation vs. elevation for BY (circles indicate valley stations, and crosses indicate non-valley stations, the trendlines are also shown in the figure).

station, i.e. by comparing the valley-mountain and valleyopen station pairs, respectively. Both tests are conducted for daily precipitation of each CP and for all days in general. In addition, the mean daily precipitation is plotted together with its standard error. To be mentioned, another advantage of the KS test over ANOVA is that it is not dependent on the sample size. For ANOVA test, the power of the statistical tests decreases, when the sample size is either too small or too large. However, in this research, we stick to a consistent significance level of 0.05 for different sample sizes.

\subsubsection{Statistical analysis of station triples in Baden-Wuerttemberg}

The station triples selected from Baden-Wuerttemberg are T1 in the Black Forest, which is a middle-range mountain, T-2 in Odenwald and T-3 in the Swabian Alps, both being low-range mountains. The exact configuration of the station triplets can be found in Fig. 13a-c.

Table 4 shows that for Zastler (valley station) and Titisee (open station) of $\mathrm{T}-1$, the null hypothesis are rejected for 

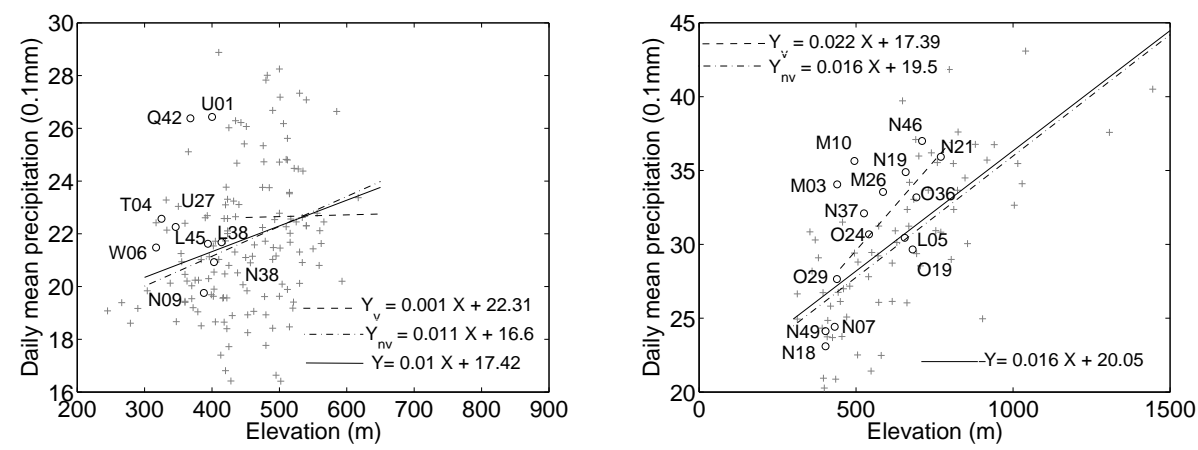

Fig. 11. Location of outliers and local scatter plot with trendlines (circles indicate valley stations, and crosses indicate non-valley stations, the trendlines are also shown in the figure).

Table 4. Statistical test results of station group in Baden-Wuerttemberg.

\begin{tabular}{|c|c|c|c|c|c|c|}
\hline \multirow[t]{2}{*}{$\mathrm{CP}$} & $n$ & $\mathrm{KS}-p$ & ANOVA- $p$ & $n$ & $\mathrm{KS}-p$ & ANOVA- $p$ \\
\hline & \multicolumn{3}{|c|}{ valley vs. mountain } & \multicolumn{3}{|c|}{ valley vs. open } \\
\hline & \multicolumn{3}{|c|}{ Zastler vs. Hofsgrund } & \multicolumn{3}{|c|}{ Zastler vs. Titisee } \\
\hline CP05 & 1362 & $(0.01)$ & 0.03 & 1362 & $(0.01)$ & $(0.00)$ \\
\hline СР09 & 1036 & $(0.00)$ & $(0.00)$ & 1036 & $(0.04)$ & $(0.00)$ \\
\hline CP10 & 390 & 0.98 & 0.91 & 390 & 0.30 & 0.06 \\
\hline CP14 & 486 & 0.15 & 0.10 & 486 & 0.27 & 0.06 \\
\hline CP17 & 910 & 0.58 & 0.21 & 910 & $(0.00)$ & $(0.00)$ \\
\hline CP18 & 1575 & 0.11 & 0.42 & 1575 & $(0.00)$ & $(0.00)$ \\
\hline \multirow[t]{2}{*}{ general } & 14668 & $(0.00)$ & 0.00 & 14668 & $(0.00)$ & $(0.00)$ \\
\hline & \multicolumn{3}{|c|}{ Eberbach vs. Waldbrunn } & \multicolumn{3}{|c|}{ Eberbach vs. Spechbach } \\
\hline CP05 & 1521 & 0.96 & 0.89 & 1521 & $(0.03)$ & $(0.01)$ \\
\hline СР09 & 1110 & 0.81 & 0.81 & 1110 & 0.27 & 0.99 \\
\hline CP10 & 436 & 0.57 & 0.76 & 436 & $(0.00)$ & $(0.00)$ \\
\hline CP14 & 548 & 0.97 & 0.95 & 548 & 0.10 & 0.15 \\
\hline CP17 & 1016 & 0.97 & 0.66 & 1016 & 0.20 & 0.15 \\
\hline CP18 & 1745 & 0.87 & 0.96 & 1745 & $(0.00)$ & $(0.00)$ \\
\hline \multirow[t]{2}{*}{ general } & 16070 & 0.24 & 0.95 & 16070 & $(0.00)$ & $(0.00)$ \\
\hline & \multicolumn{3}{|c|}{ Eningen vs. Urbach } & \multicolumn{3}{|c|}{ Reutlingen vs. Urbach } \\
\hline CP05 & 366 & 1.00 & 0.87 & 926 & 0.24 & 0.21 \\
\hline СР09 & 259 & 0.83 & 0.81 & 666 & $(0.00)$ & $(0.00)$ \\
\hline CP10 & 78 & 0.65 & 0.44 & 259 & $(0.00)$ & $(0.00)$ \\
\hline CP14 & 137 & 0.99 & 0.54 & 341 & 0.06 & $(0.01)$ \\
\hline $\mathrm{CP} 17$ & 224 & 0.94 & 0.87 & 633 & 0.91 & 0.24 \\
\hline CP18 & 396 & 0.35 & 0.55 & 1084 & $(0.00)$ & $(0.00)$ \\
\hline general & 3561 & 0.16 & 0.88 & 9862 & $(0.00)$ & $(0.00)$ \\
\hline
\end{tabular}

CP05(SW), CP09(NE), CP17(SW) and CP18(W), by which the station is shielded from the CP direction. The null hypothesis that Zastler and Hofsgrund (mountain station) have similar CDFs cannot be rejected except for CP05 (SW) and CP09 (NE), which according to our hypothesis, should behave similarly because Zastler is shielded. Closer investigation shows there is a northeast-oriented slope, by which the elevation decreases from Hofsgrund to Zastler. Because the precipitation gradient in this direction cannot be excluded, the tests are not able to obtain exact results, which considers the mountain-valley effect only. For this triplet, the ANOVA tests did not provide any additional information.

For both T-2 and T-3, the null-hypothesis that the precipitation time series of the mountain and valley stations are from the same population cannot be rejected for all CPs, nor for general days. On the contrary, the null-hypotheses are in most cases rejected for the open-valley station pairs for the two triples. For T-2, the null hypothesis cannot be 


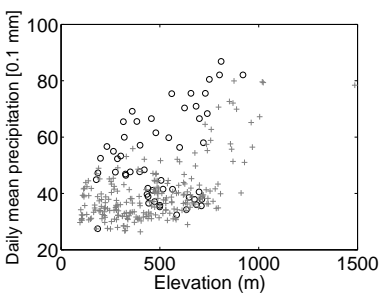

(a) $\mathrm{CP} 05$

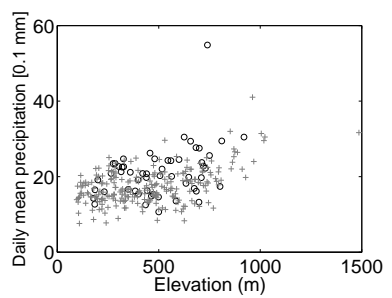

(d) $\mathrm{CP} 14$

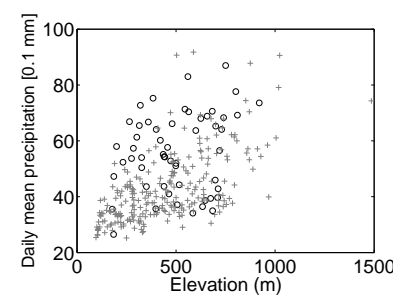

(b) $\mathrm{CP} 09$

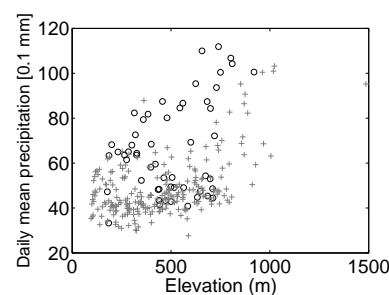

(e) $\mathrm{CP} 17$

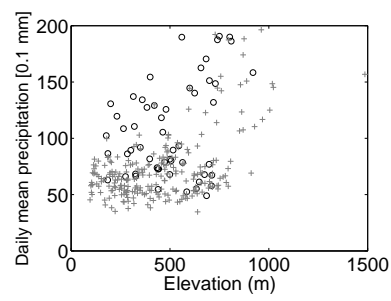

(c) $\mathrm{CP} 10$

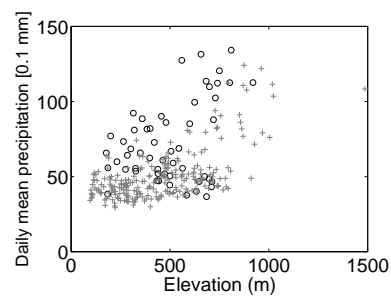

(f) $\mathrm{CP} 18$

Fig. 12. Scatter plot of mean daily precipitation of wet CPs for BW (circles indicate valley stations, and crosses indicate non-valley stations, the trendlines are also shown in the figure).

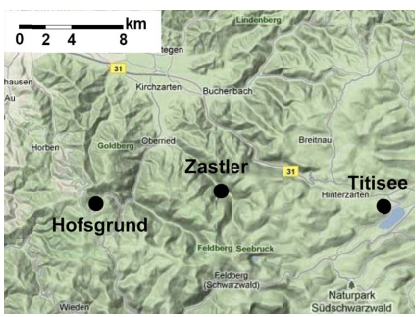

(a) $\mathrm{T}-1$

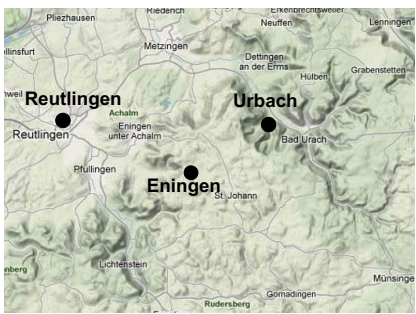

(c) T-3

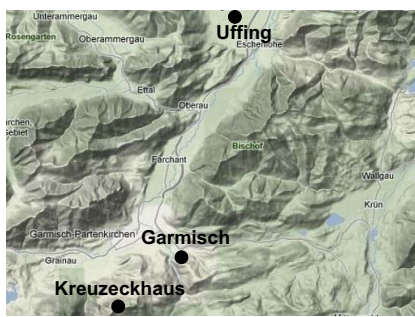

(e) $\mathrm{T}-5$

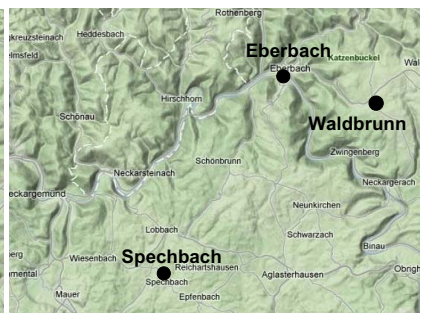

(b) $\mathrm{T}-2$

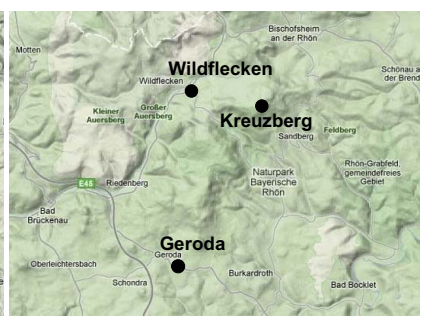

(d) T-4

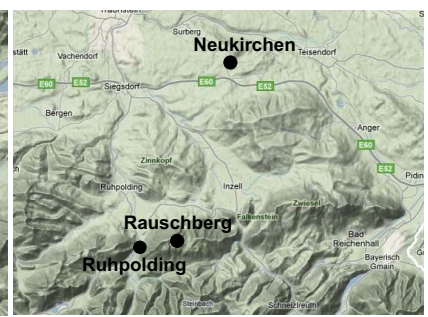

(f) T-6
Fig. 13. Detailed topography of the selected the station groups. rejected for $\mathrm{CP} 09$ or $\mathrm{CP} 17$, for which the valley is parallel to the CPs. Furthermore, $H_{0}$ is rejected for the northwest-facing CP10 (NW) and CP18 (W), the valley for which is perpendicular to the CPs. Although for CP14 (NW) which is also northwest-facing, the null hypothesis can be rejected for neither the valley-mountain nor the valley-open stations pairs, but the $p$ values are as high as 0.97 for the mountain-valley pair, which indicates a nearly identical CDF, whereas for the mountain-open pair it is only 0.1 , indicating very less similarity. CP5 (SW) is an exception in this case, the analysis of which is beyond the scope of this paper.

For T-3, the valley and mountain stations receive similar precipitation in all cases, while only in very rare cases do the valley stations behave similarly to the open stations. The null hypothesis for the valley-open station pair are rejected for CP9 (NE), CP10 (NW), CP18 (W), the CP for which is not aligned in the valley direction. However, according to the assumption, the null hypothesis for the valley-open station pair should be rejected for CP5 (SW) and CP17 (SW) too, the $\mathrm{CP}$ for which is perpendicular to the valley orientation, but in reality is not the case. Closer investigation of the mean precipitation amounts in Fig. 14c shows the mean precipitation at station Urbach is more closer to the mountain station Eningen than to the open station Reutlingen.

It is worth mentioning that in addition to the valley effects, the wind-drift effects at small scale also influence the precipitation pattern, i.e. local enhancement of precipitation at the windward side of the valley. As for CP05 (SW) and CP09 (NE), the precipitation at the valley station Eberbach is even slightly higher than the mountain station Waldbrunn. 


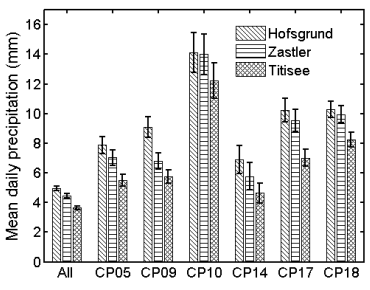

(a) $\mathrm{T} 1$

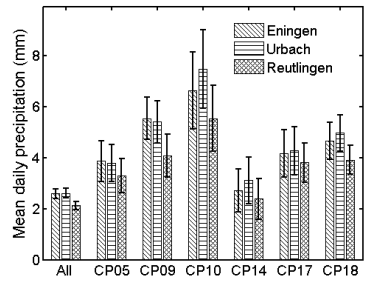

(c) $\mathrm{T} 3$

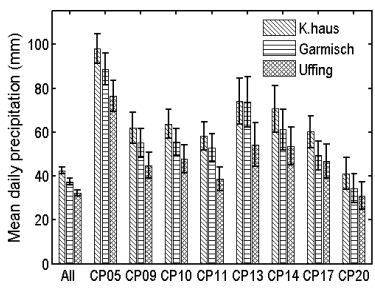

(e) $\mathrm{T} 5$

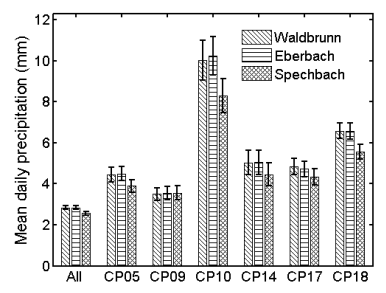

(b) $\mathrm{T} 2$

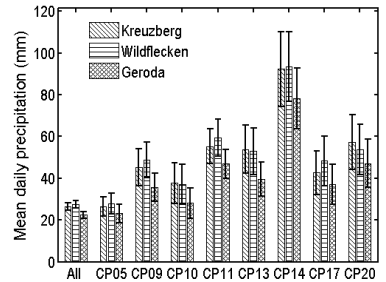

(d) $\mathrm{T} 4$

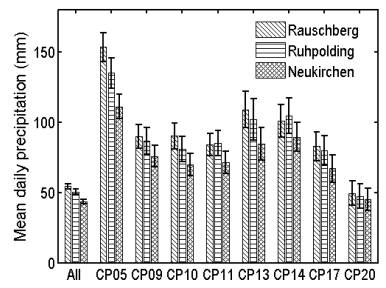

(f) T6
Fig. 14. Mean precipitation of each wet CP for the selected station groups.

\subsubsection{Statistical analysis of station triples in Bavaria}

In Bavaria, T-4 in the middle-range Rhoen Mountains in the north and T-5/T-6 in the high-range Alps in the south are taken for statistical investigation (see Fig. 13d-f). The mean daily precipitation plotted in Fig. 14d-f) shows that the precipitation at the valley station is much closer to that at the mountain station and sometimes even higher. The precipitation at the open station is lowest for all three triplets. As it can be seen from Table 5, the null-hypotheses are rejected at the significance level of $\alpha=0.05$ for all three triplets when general days are studied. However, the test statistics vary for different CPs, which is subjected to the following investigation considering the interaction of the valley with the CPs.

As for T-4, the valley is southwest oriented. The test statistics show that the null hypothesis is rejected at the significance level of $\alpha=0.05$ for the mountain-valley station pair (Kreuzberg-Wildflecken) in the case of CP05 (SW), parallel to the valley, while the null hypothesis cannot be rejected for the valley-open station pair as shown in Table 5, confirming the above assumption of the interaction between valleys and CPs. For the valley-open station pair, the null hypotheses are rejected for CP09 (W), CP11 (NW), CP13 (N), which are not aligned with the valley. For CP17 $(\mathrm{N})$, even though the null
Table 5. Statistical test results of station group in Bavaria.

\begin{tabular}{|c|c|c|c|c|c|c|}
\hline \multirow[t]{2}{*}{$\mathrm{CP}$} & $n$ & $\mathrm{KS}-p$ & ANOVA- $p$ & $n$ & $\mathrm{KS}-p$ & ANOVA- $p$ \\
\hline & \multicolumn{3}{|c|}{ valley vs. mountain } & \multicolumn{3}{|c|}{ valley vs. open } \\
\hline & \multicolumn{3}{|c|}{ Kreuzberg vs. Wildflecken } & \multicolumn{3}{|c|}{ Wildflecken vs. Gerode } \\
\hline $\mathrm{CP} 05$ & 382 & $(0.05)$ & 0.69 & 382 & 0.17 & 0.29 \\
\hline CP09 & 227 & 0.12 & 0.58 & 227 & $(0.02)$ & 0.06 \\
\hline $\mathrm{CP} 10$ & 224 & 0.76 & 0.92 & 224 & 0.15 & 0.18 \\
\hline CP11 & 273 & 0.58 & 0.49 & 273 & $(0.03)$ & $(0.05)$ \\
\hline CP13 & 127 & 0.99 & 0.91 & 127 & 0.05 & 0.25 \\
\hline CP14 & 125 & 0.99 & 0.93 & 125 & 0.18 & 0.31 \\
\hline $\mathrm{CP} 17$ & 136 & 0.92 & 0.48 & 136 & 0.15 & 0.54 \\
\hline $\mathrm{CP} 20$ & 113 & 0.85 & 0.69 & 113 & 0.44 & 0.42 \\
\hline \multirow[t]{2}{*}{ general } & 3957 & $(0.00)$ & 0.46 & 3957 & $(0.00)$ & $(0.00)$ \\
\hline & \multicolumn{3}{|c|}{ Kreuzeckhaus vs. Garmisch } & \multicolumn{3}{|c|}{ Garmisch vs. Uffing } \\
\hline CP05 & 842 & $(0.00)$ & 0.06 & 842 & $(0.00)$ & $(0.01)$ \\
\hline CP09 & 615 & 0.11 & 0.17 & 615 & 0.05 & $(0.02)$ \\
\hline CP10 & 561 & 0.10 & 0.07 & 561 & $(0.03)$ & 0.09 \\
\hline CP11 & 637 & 0.06 & 0.24 & 637 & $(0.01)$ & 0.00 \\
\hline CP13 & 316 & 0.27 & 0.97 & 316 & $(0.01)$ & $(0.01)$ \\
\hline CP14 & 348 & 0.48 & 0.19 & 348 & 0.18 & 0.21 \\
\hline $\mathrm{CP} 17$ & 392 & 0.10 & $(0.03)$ & 392 & 0.27 & 0.64 \\
\hline $\mathrm{CP} 20$ & 306 & 0.29 & 0.18 & 306 & 0.80 & 0.42 \\
\hline \multirow[t]{2}{*}{ general } & 9861 & $(0.00)$ & $(0.00)$ & 9861 & $(0.00)$ & $(0.00)$ \\
\hline & \multicolumn{3}{|c|}{ Rauschberg vs. Ruhpolding } & \multicolumn{3}{|c|}{ Ruhpolding vs. Neukirchen } \\
\hline CP05 & 1061 & $(0.00)$ & $(0.01)$ & 809 & $(0.00)$ & $(0.00)$ \\
\hline СР09 & 803 & 0.08 & 0.60 & 590 & 0.51 & 0.07 \\
\hline CP10 & 762 & 0.11 & 0.13 & 562 & 0.35 & 0.07 \\
\hline CP11 & 801 & 0.39 & 0.93 & 602 & 0.20 & $(0.03)$ \\
\hline CP13 & 405 & 0.15 & 0.44 & 315 & 0.41 & 0.07 \\
\hline CP14 & 448 & 0.99 & 0.67 & 337 & 0.35 & 0.07 \\
\hline CP17 & 487 & 0.39 & 0.36 & 349 & 0.24 & 0.08 \\
\hline $\mathrm{CP} 20$ & 401 & 0.90 & 0.68 & 304 & 0.94 & 0.70 \\
\hline ALL & 13058 & $(0.00)$ & $(0.00)$ & 9952 & $(0.00)$ & $(0.00)$ \\
\hline
\end{tabular}

hypothesis is not rejected, the $p$ value for the valley-open station pair is relatively low compared to the mountain-valley pair, 0.15 to 0.54 in this case, which indicates that the valley station behaves more similarly to the mountain station than to the open station. Figure $14 \mathrm{~d}$ also shows that the mean precipitation at Kreuzberg and Wildflecken is almost identical, whereas the difference of precipitation amount between Wildflecken and Geroda are very distinct.

The valley station Garmisch from T-5 is located at a bifurcation of three valleys: one west-facing, one northeast-facing and one northwest-facing. As shown in Table 5, the precipitation time series of the valley station Garmisch and the mountain station Kreuzeckhaus are very similar, except for CPs coming in any of the three valley directions, e.g. CP05(SW), $\mathrm{CP11}(\mathrm{NW})$. For each of these cases, at least one of the test hypotheses is rejected or very close to the selected significance level $\alpha=0.05$. Because the valley station Garmisch is deep in the mountain, it more closely resembles the mountain station than the open station Uffing in general. Figure 14e shows that the precipitation amount at the valley station is always between the open station and the mountain station and it converges at the open station when CPs are parallel to the valley orientation and vice versa. 


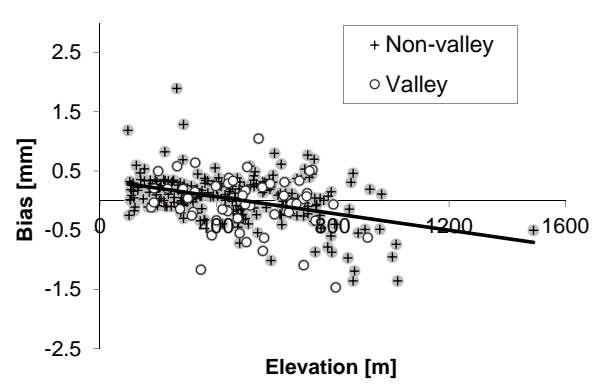

(a) $\mathrm{OK}$

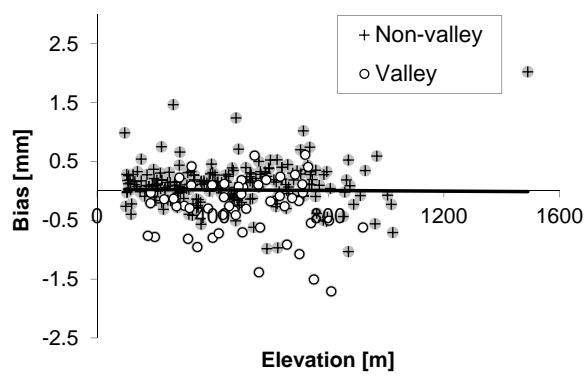

(b) EDK

Fig. 15. Bias of valley and non-valley stations for cross-validation of OK and EDK for Baden-Wuerttemberg over $1960--2007$.

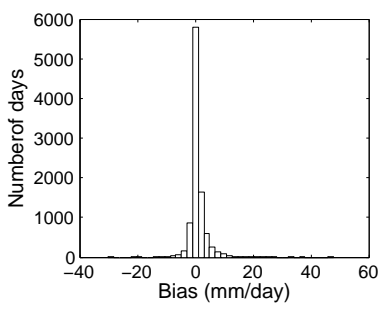

(a) $\mathrm{OK}$

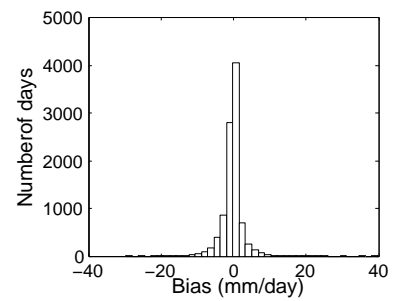

(b) EDK

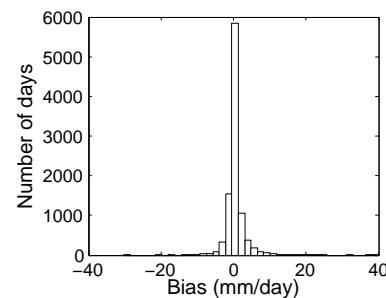

(c) EDK with surrogate

Fig. 16. Histogram of bias for different interpolation procedures at the station Zastler.

For T-6, the valley station Rhupolding lies in a gap of the east-west-facing mountain ridge, and the valley station is open to northeast direction. For the west-facing CP20 (W), both tests for both pairs cannot reject the null-hypotheses, which means there is an even areal precipitation. For most CPs (CP09 (W), CP11 (NW), CP13 (N), CP14 (W), CP17 (N)) that are not parallel to the valley orientation, i.e. northeast, the null hypotheses cannot be rejected at or close to the significance level of $\alpha=0.05$ for the valley-mountain station pairs by either test, whereas they are rejected for the valley-open station pair by One-way ANOVA. This can also be confirmed by the mean precipitation for each $\mathrm{CP}$ plotted in Fig. 14f. For CP10 (E) from the east, the valley station seems to be partially open to the moisture flow, therefore it behaves differently from both the mountain and the valley station.

From the statistical analysis of the six mountain-valleyopen station triplets, it confirms the assumption that the valley station always receives more precipitation than an open station at the same elevation, and there is an interaction between the valley and the $\mathrm{CP}$. When the valley is shielded from the moisture flow, the precipitation within the valley is comparable to the precipitation on the mountain crest and both are higher than the precipitation on the open area; when the valley is open to the moisture flow, the precipitation within the valley is much less than on the mountain and closer to the open area. Such effect can only be observed for the secondary narrow and steep valleys, and is referred to as the "narrowvalley effect" in this work. It is worth mentioning that topographic modification of precipitation distribution is a com- plex procedure involving many processes, such as orographic gradient and WDR, etc., the "narrow-valley effect" can be observed only when other effects can be properly excluded.

\section{Consequence of neglecting the valley effects}

The spatial precipitation patterns caused by the interaction of valley and CP are not accounted for in many hydrological applications, for example, the spatial interpolation of precipitation. Not only in the simple procedures, such as Thiessen Polygon or inversed distance, but also in the more advanced geostatistical methods of Kriging, such as OK or EDK, are such intermediate-scale patterns neglected. Although EDK has taken the topographic effect into the consideration of the interpolation, the linear relationship can account for the orographic effect at the large scale, but it fails to include the valley effect discussed in this work. Therefore all these techniques produce unavoidable bias in the interpolation results, which is hidden when the overall error for all stations, such as mean squared error is applied as evaluation criteria for the interpolation results. As an example, cross-validation with both OK and EDK has been performed on $47 \mathrm{yr}(1960--2007)$ daily precipitation data. Figure 15 shows the station-wise mean bias of the valley and non-valley stations, respectively, for the data in Baden-Wuerttemberg. Figure 15a shows the bias of OK, which exhibits a systematic trend for both valley and non-valley stations, when the orographic effect is completely neglected. Consideration of the orographic effect 
by EDK reduces the bias, leading to more randomly distributed errors if all stations are counted, but a systematic bias of valley and non-valley stations has been generated artificially. For valley stations, EDK gives a negative mean bias $(\hat{Z}-Z)$ of around $-0.4 \mathrm{~mm}$, with a mean bias of around $0.10 \mathrm{~mm}$ for the non-valley stations, i.e. there is an essential underestimation for the valley stations and a slight overestimation for the non-valley stations. As shown in Fig. 15, the bias is not so significant at lower elevations, e.g. less than $600 \mathrm{~m}$, but becomes dramatic at higher elevation, e.g. in the mountainous area.

By adjusting the elevation of the stations to the orographic surrogate elevation during the EDK procedure according to the $\mathrm{CP}$ direction, the interaction of valley and the $\mathrm{CP}$ will be considered, and consequently the interpolation results should be improved. The orographic surrogate elevation is a weighted average elevation of the area surrounding the station. As an experiment, a $5.0 \mathrm{~km} \times 1.25 \mathrm{~km}$ area is used, and the points are weighted using an inverse distance method. A cross-validation experiment is carried out for the valley station Zastler. First, the precipitation at the station is interpolated using OK and EDK with actual station elevation as auxiliary information, assuming no observation at Zastler. Then the cross-validation is repeated by adjusting the elevation to the surrogate elevation used in the EDK according to CPs. Figure 16 shows the histogram of the bias for the three different interpolation of 5400 raining days. The underestimation by EDK and overshooting by OK can be observed again by the histogram. The mean absolute bias EDK with surrogate is $2.00 \mathrm{~mm}$, which is the minimum, and for $\mathrm{OK}$ $2.18 \mathrm{~mm}$ and EDK $2.410 \mathrm{~mm}$.

\section{Conclusions}

The spatial precipitation pattern at the intermediate scale has been investigated in this research. Scatter plots of precipitation to elevation have confirmed the interaction between the secondary narrow and steep valleys and the CPs in the complex terrain, which is referred to as the "narrowvalley effect". Non-parametric KS test and parametric Oneway ANOVA test with selected station triplets have further demonstrated the precipitation patterns in mountain ranges of different elevation from low, medium to high. Although some exceptional cases where the test statistics do not show a very clear dependence on CPs, due to local complexity of microtopographic configuration and the interference of the large-scale orographic precipitation gradient, a general interaction rule can be concluded, i.e. if the valley is open to the moisture flow, it behaves more similarly to the open station and differently from the mountain station and vice versa.

Such spatial variability of the precipitation is usually neglected by widely applied interpolation techniques, even the more advanced ones, such as OK and EDK. Cross-validation using $\mathrm{OK}$ and EDK has demonstrated that completely ne- glecting topography in $\mathrm{OK}$ leads to a systematic drift of errors, whereas consideration of elevation with an overall linear relationship causes overestimation at the mountains and underestimation in the valleys. An experiment with EDK applying the orographic surrogate elevation shows the potential to improve the interpolation results. This work has pointed out a blind spot in the spatial statistics of precipitation and calls for future research to account for the "narrow-valley effect".

Acknowledgements. This research was supported by the National Natural Science Foundation of China (Project No. 41101020). The authors thank the German Federal Ministry of Education and Research (BMBF) and the International Doctoral Program Environment Water (ENWAT) at the University of Stuttgart for support of the research. Special thanks to the anonymous reviewers for their constructive comments for improving and finalizing the article.

Edited by: R. Uijlenhoet

\section{References}

Anders, A. M., Roe, G. H., Montgomery, D. R., and Finnegan, N. J.: Spatial patterns of precipitation and topography in the Himalaya, Society, 2398, 39-53, doi:10.1130/2006.2398(03), 2006.

Arnaud, P., Bouvier, C., Cisneros, L., and Dominguez, R.: Influence of rainfall spatial variability on flood prediction, J. Hydrol., 260, 216-230, doi:10.1016/S0022-1694(01)00611-4, 2002.

Bárdossy, A.: Atmospheric circulation pattern classification for South-West Germany using hydrological variables, Phys. Chem. Earth, 35, 498-506, doi:10.1016/j.pce.2010.02.007, 2010.

Bárdossy, A., Stehlík, J., and Caspary, H.-J.: Automated objective classification of daily circulation patterns for precipitation and temperature downscaling based on optimized fuzzy rules, Clim. Res., 23, 11-22, 2002.

Bárdossy, A., Bogardi, I., and Matyasovszky, I.: Fuzzy rule-based downscaling of precipitation, Theor. Appl. Climatol., 82, 119129, doi:10.1007/s00704-004-0121-0, 2005.

Basist, A., Bell, G. D., and Meentemeyer, V.: Statistical relationships between topography and precipitation patterns, J. Climate, 7, 1305-1315, 1994.

Bidin, K. and Chappell, N. A.: Technical Note: small humid tropical catchment, October, 7, 245-253, 2003.

Blocken, B., Carmeliet, J., and Poesen, J.: Numerical simulation of the wind-driven rainfall distribution over small-scale topography in space and time, J. Hydrol., 315, 252-273, doi:10.1016/j.jhydrol.2005.03.029, 2005.

Busuioc, A., Chen, D., and Hellstrom, C.: Temporal and spatial variability of precipitation in Sweden and its link with the large-scale atmospheric circulation, Tellus A, 53, 348-367, doi:10.1034/j.1600-0870.2001.01152.x, 2001.

Cheng, K.-S., Lin, Y.-C., and Liou, J.-J.: Rain-gauge network evaluation and augmentation using geostatistics, Hydrol. Process., 22 2554-2564, doi:10.1002/hyp.6851, 2008.

Daly, C., Gibson, W. P., Taylor, G. H., Johnson, G. L., and Pasteris, P.: A knowledge-based approach to the statistical mapping of climate, Clim. Res., 22, 99-113, 2002. 
Faures, J., Goodrich, D., Woolhiser, D., and Sorooshian, S.: Impact of small-scale spatial rainfall variability on runoff modeling, J. Hydrol., 173, 309-326, 1995.

Fekete, B. M., Vörösmarty, C. J., Roads, J. O., and Willmott, C. J.: Uncertainties in precipitation and their impacts on runoff estimates, J. Climate, 17, 294, doi:10.1175/15200442(2004)017<0294:UIPATI>2.0.CO;2, 2004.

Frei, C. and Schär, C.: A precipitation climatology of the Alps from high-resolution rain-gauge observations, Int. J. Climatol., 18, 873-900, 1998.

Haston, L. and Michaelsen, J.: Spatial and temporal variability of southern California precipitation over the last $400 \mathrm{yr}$ and relationships to atmospheric circulation patterns, J. Climate, 10, 1836-1852, 1997.

Haven, N.: A linear theory of orographic precipitation, J. Atmos. Sci., 61, 1377-1391, 2004.

Houze, R.: Cloud Dynamics, chap. Orograpic clouds, 502-238, Academic Press, California, 1993.

Jeniffer, K., Su, Z., Woldai, T., and Maathuis, B.: Estimation of spatialtemporal rainfall distribution using remote sensing techniques: a case study of Makanya catchment, Tanzania, Int. J. Appl. Earth Obs., 12, 90-99, doi:10.1016/j.jag.2009.10.003, 2010.

Jiang, Q.: Precipitation over multiscale terrain, Tellus A, 59, 321335, doi:10.1111/j.1600-0870.2007.00232.x, 2007.

Johansson, B. and Chen, D.: The influence of wind and topograpy on precipitation distribution in Sweden: statistical analysis and modelling, Int. J. Climatol., 23, 1523-1535, doi:10.1002/joc.951, 2003.

Koren, V., Finnerty, B., Schaake, J., Smith, M., Seo, D., and Duan, Q.: Scale dependencies of hydrologic models to spatial variability of precipitation, J. Hydrol., 217, 285-302, doi:10.1016/S0022-1694(98)00231-5, 1999.

Krischnaiah, P. R.: 7 Robustness of ANOVA and MANOVA test procedures, Analysis of Variance, Series: Handbook of Statistics, 1, 199-236, 1980.

Langella, G., Basile, A., Bonfante, A., and Terribile, F.: High-resolution spacetime rainfall analysis using integrated ANN inference systems, J. Hydrol., 387, 328-342, doi:10.1016/j.jhydrol.2010.04.027, 2010.

Lehning, M., Lo, H., Ryser, M., and Raderschall, N.: Inhomogeneous precipitation distribution and snow transport in steep terrain, Water Resour. Res., 44, 1-19, doi:10.1029/2007WR006545, 2008.

Marquínez, J., Lastra, J., and García, P.: Estimation models for precipitation in mountainous regions: the use of GIS and multivariate analysis, J. Hydrol., 270, 1-11, doi:10.1016/S00221694(02)00110-5, 2003.
Merz, B. and Bárdossy, A.: Effects of spatial variability on the rainfall runoff process in a small loess catchment, J. Hydrol., 212213, 304-317, doi:10.1016/S0022-1694(98)00213-3, 1998.

Montgomery, D. R.: Valley formation by fluvial and glacial erosion, Geology, 30, 1047, doi:10.1130/00917613(2002)030<1047:VFBFAG>2.0.CO;2, 2002.

Nezlin, N. and Stein, E.: Spatial and temporal patterns of remotely-sensed and field-measured rainfall in southern California, Remote Sens. Environ., 96, 228-245, doi:10.1016/j.rse.2005.02.005, 2005.

Prudhomme, C. and Reed, D. W.: Relationships between extreme daily precipitation and topography in a mountainous region: a case study in Scotland, Int. J. Climatol, 18, 1439-1453, 1998.

Roe, G. H., Montgomery, D. R., and Hallet, B.: Orographic precipitation and the relief of mountain ranges, J. Geophys. Res., 108, 2315, doi:10.1029/2001JB001521, 2003.

Sevruk, B. and Nevenic, M.: The geography and topography effects on the areal pattern of precipitation in a small prealpine basin, Water Sci. Technol., 37, 163-170, doi:10.1016/S02731223(98)00329-1, 1998.

Sharon, D. and Arazi, A.: The distribution of wind-driven rainfall in a small valley: an empirical basis for numerical model verification, J. Hydrol., 201, 21-48, doi:10.1016/S0022-1694(97)000346, 1997.

Smith, R. B.: Progress on theory of orographic precipitation, Geological Society of America special paper 398, Tectonics, Climate and Landscape Evolution, 1-16, 2006.

Stolar, D., Roe, G., and Willett, S.: Controls on the patterns of topography and erosion rate in a critical orogen, Water Resour. Res., 112, 1-17, doi:10.1029/2006JF000713, 2007.

Sun, R., Zhang, B., and Tan, J.: A multivariate regression model for predicting precipitation in the Daqing Mountains, Mt. Res. Dev., 28, 318-325, doi:10.1659/mrd.0944, 2008.

Wastl, C. and Zängl, G.: Analysis of mountain-valley precipitation differences in the Alps, Meteorol. Z., 17, 311-321, doi:10.1127/0941-2948/2008/0291, 2008.

Weisse, A. K. and Bois, P.: Topographic effects on statistical characteristics of heavy rainfall and mapping in the French Alps, J. Appl. Meteorol., 40, 720-740, 2001.

Younger, P. M., Freer, J. E., and Beven, K. J.: Detecting the effects of spatial variability of rainfall on hydrological modelling within an uncertainty, Hydrol. Process., 2003, 1988-2003, doi:10.1002/hyp, 2009. 